\title{
Intelligent Shutter System Design of Photovoltaic Power Generation Based on Single Chip Microcomputer Control
}

\author{
QU Mingfei ${ }^{1, a}$, ZHAO Dan ${ }^{1, b}$ \\ ${ }^{1}$ College of automation engineering, Beijing polytechnic, Beijing 100176, China \\ aqumingfei@126.com, ${ }^{b}$ zdddky@163.com
}

Keyword: intelligent shutter system, photovoltaic power generation, energy efficiency

\begin{abstract}
Photovoltaic industry is a new energy industry, it uses the solar cells directly convert to electricity production, it is a new development production in the new century, it develops rapidly. In this paper, the new energy development and utilization are taken as the base, the intelligent shutter system of photovoltaic power generation is designed, solar photovoltaic system not only operates in the strong sunlight, it can also work and generate power in cloudy inexhaustibly. The environmental pollution caused by the use of solar energy will be reduced, soit is an ideal green energy. An intelligent shutter system of photovoltaic power generation isproposed based on single chip microcomputer control, photovoltaic power generation system is established based on individual family, it can provide the electricity demand in the room, of course, the intelligent shutter system also takes electricity without environmental pollution at the same time, it can meet the requirements of the intelligent home furnishing.
\end{abstract}

\section{Introduction}

With the progress of science and technology and the rapid development of economy, the intelligent Home Furnishing, and Internet of things technology have taken a rapid development and progress, at the same time, a greener, more efficient, and inexhaustible energy source -- solar energy also enters the high-speed train of the human science and technology development, along with the rapid development of photovoltaic industry, Chinese energy industry is also faced with the "big shake", although the old energy sources cannot be discarded completely, to meet the "new energy", "energy efficiency" still has a long way to go, no doubt, the direction is right. This paper designed an intelligent louver photovoltaic power generation system based on single-chip microcomputer control, to solve the problem of primary sources and channels of clean household energy, at the same time, the design of remote intelligent control and synchronous display of status data is obtained, through the simulation experiment, it verifies the feasibility of the system design[1-3].

\section{Overall design scheme of system}

\section{A System function goal}

(1) Receiving sunlight photovoltaic panels, convert solar energy into electrical energy, which is stored in the battery;

(2) Battery electric energy can be used for the whole system operation, it is the sources of energy;

(3) Louver system can be composed of infrared remote control opening and closing without direct contact.

\section{B Frame structure of system}

The photovoltaic intelligent shutter system is composed of three subsystems: photovoltaic power generation system, energy distribution system, intelligent shutter system[4,5].

(1) The photovoltaic power generation system is responsible for the portion of the received light energy into electrical energy, storage batteries are charged by direct charging, and the electric energy is stored; 
(2) Energy distribution system is assigned to different power regulators respectively, electrical appliances are used, servo motor and control system are designed, and the shutter movement control center -- such as microcontroller are designed.

(3) The intelligent shutter system is responsible for the control of the owner to make the corresponding action.

The three subsystems are combined organically, it is shown in Figure 1, a complete photovoltaic intelligent shutter system is obtained.

Through the organic combination of the three subsystems, as shown in Figure 1, constitute a complete photovoltaic intelligent shutter system.

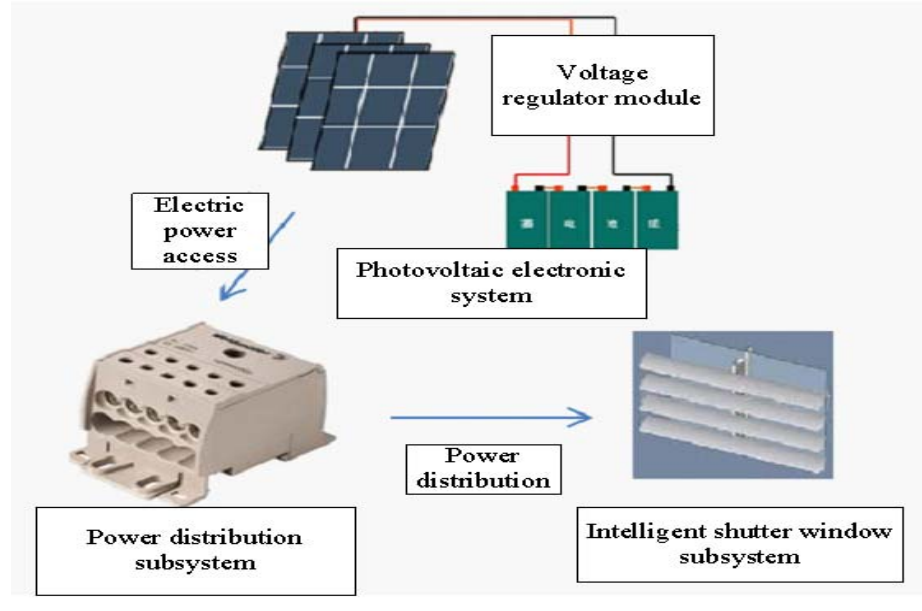

Figure 1 System structure diagram of photovoltaic power generation intelligent shutter

\section{Design of each subsystems}

\section{A Photovoltaic electronic subsystem}

Photovoltaic electronic system consists of photovoltaic panels with $10 \mathrm{~W}$ power, it has vol tage regulator module with real-time display, automatic up-down $12 \mathrm{~V}$ battery etc. When pho tovoltaic panels receive enough light, voltage will produce some fluctuation, it needs to cha rge the battery, and it is composed of a voltage stabilizing module voltage to $13.5 \mathrm{~V}$, namel y direct charging method.

(1) Photovoltaic plate of $10 \mathrm{~W}$ power

Photovoltaic panel uses $18 \mathrm{~V}$ rated voltage and polycrystalline solar panel with $10 \mathrm{~W}$ rated power.

(2) Voltage regulator module

Voltage regulator module is a kind of real-time voltage display adjustable voltage regulat or module with automatic lifting pressure, the output of PV panels end is connected with $t$ he input end of the voltage regulator module, output voltage regulator module end is string into the Hexapod key access battery switch, when the battery is full, it can close the regu lator module output end of the Hexapod button switch, and stop charging protect for the ba ttery.

(3) $12 \mathrm{~V}$ battery

The $12 \mathrm{~V}$ battery is the main energy storage component, it is the whole system energy $\mathrm{s}$ ource, two 6V5Ah connected in series in the battery.

\section{B Energy distribution system}

Energy distribution subsystem is integrated in a block by $5 \mathrm{~V}$ voltage regulator module a nd some power indicator and other peripheral circuit, input end battery access $5 \mathrm{~V}$ voltage $\mathrm{r}$ egulator module, the output end is connected with a six legged button switch and a power indicator lamp, it is composed of two groups of row after welded into a unified power sup ply area, it needs to take the electric equipment, thus module access and electric are realize d. 


\section{Intelligent louver window system}

The intelligent shutter window system is comprised with a servo motor, STC89C52 MCU development board, a buzzer circuit, infrared remote control circuit, when the infrared remote control button is pressed, the infrared receiving circuit receives the infrared signal, the I/O port of the SCM is input in the system, then the MCU decoding is obtained, signal codes are decoded into the specified letter number, the servo motor action is triggering, which can achieve remote control shutter opening and closing.

(1) Servo motor

The system uses a MG995 servo motor, the working voltage is .8-7.2 $\mathrm{V}$, work dead area is $5 \mathrm{us}$, it has tension with $9.4 \mathrm{~kg} / \mathrm{cm}(4.8 \mathrm{~V}), 11 \mathrm{~kg} / \mathrm{cm}(6 \mathrm{~V})$, the PWM pulse width control is taken, and the $20 \mathrm{~ms}$ cycle signal is produced, the relationship between input signal and output angle of PWM pulse width is shown in Figure 2. The figure shows this experiment requires two angles of $0^{\circ}$ and $45^{\circ}$, and $1.5 \mathrm{~ms}$ and $2 \mathrm{~ms}$ pulse width

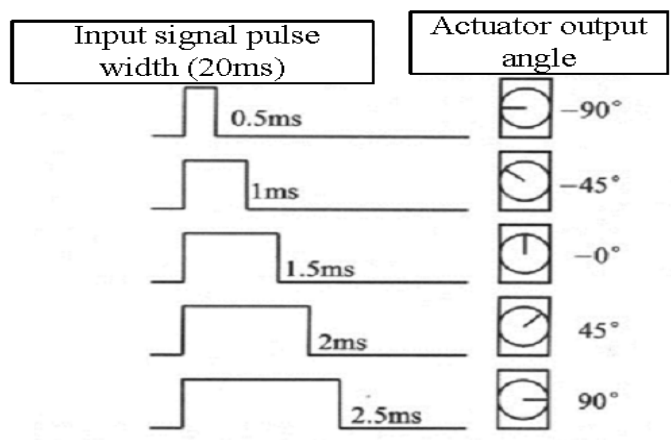

Figure 2 Relationship between input signal and output angle of PWM pulse width

(2) STC89C52 MCU development board

SCM is the core control components of intelligent louver window system, STC89C52 M CU development board has two external interrupts, two timer interrupts and a serial port int errupt. When the infrared is receiving head infrared signal, the signal end of the signal fro $\mathrm{m}$ the I/O input port of MCU external interrupt and trigger, it begins by decoding infrared remote control system, the block diagram is shown in Figure 3. At the same time, the timi ng cycle is $0.5 \mathrm{~ms}$, for generating a signal of PWM wave as the servo motor control, the MCU system flow diagram is shown in Figure 3.

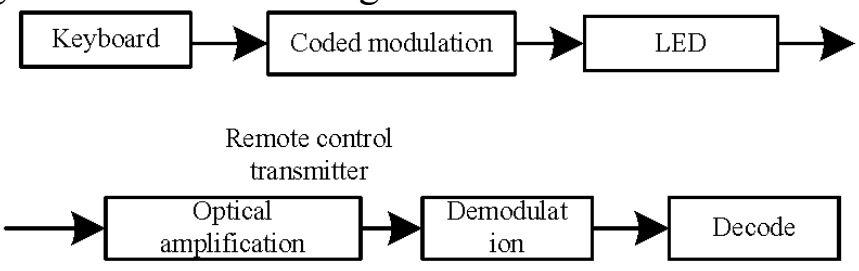

Remote control receiver

Figure 3 Block diagram of infrared remote control system

(3) Buzzer circuit

The buzzer circuit is composed of a non-polar buzzer, a NPN triode, $2 \mathrm{~K}$ resistor and ca pacitor polarity composition, when the signal buzzer signal receives a certain frequency, it c an produce sound, it is used for infrared decoding, the servo motor makes corresponding ac tion, so it is effective to inform the operator.

(4) Infrared remote control circuit

Infrared remote control circuit is composed of an infrared receiving head, $10 \mathrm{uF}$ capacitor polarity, 200 resistor composition, when the universal infrared remote controller transmits $t$ he infrared signal, it is received by the signal receiving head, and the infrared receives hea $\mathrm{d}$ code, it will enter a series of binary code to the microcontroller, including the boot code, user ID, user identification code violation, the operation code, operation complement code. Only the operation code and operating code complement are not the same, it needs to be $d$ ecoded for recognition. 


\section{Simulation results}

The simulation results complete the design requirements of the experiment basically, it in cludes the photovoltaic power generation system, energy distribution system and intelligent $\mathrm{s}$ hutter system, the system design is shown in Figure 4 and Figure 5.

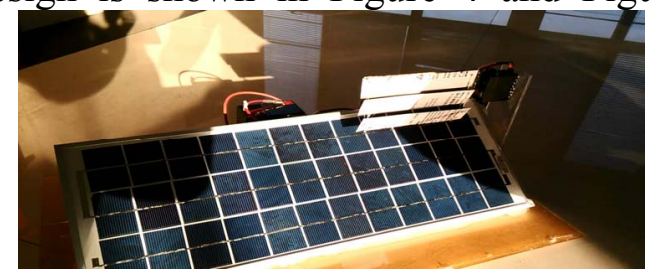

Figure 4. Photovoltaic power generation system

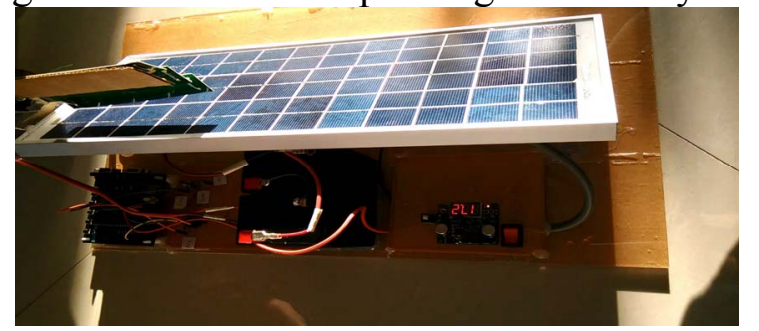

Figure 5. Energy distribution and intelligent shutter system

\section{Conclusion}

In this paper, the photovoltaic power generation system is researched and designed, and $\mathrm{t}$ he photovoltaic industry is a new energy industry, it uses the solar cells directly convert to electricity production, it is a new development production in the new century, it develops rapidly. In this paper, the new energy development and utilization are taken as the base, th e intelligent shutter system of photovoltaic power generation is designed, solar photovoltaic system not only operates in the strong sunlight, it can also work and generate power in clo udy inexhaustibly. The environmental pollution caused by the use of solar energy will be re duced, so it is an ideal green energy. An intelligent shutter system of photovoltaic power $g$ eneration is proposed based on single chip microcomputer control, photovoltaic power gener ation system is established based on individual family, it can provide the electricity demand in the room, of course, the intelligent shutter system also takes electricity without environ mental pollution at the same time, it can meet the requirements of the intelligent home fur nishing, simulation experimental results are quite satisfying.

\section{References}

[1] ZHEN Jian-jun, ZHANG Yi, HU Guang-bo. Research on Inductive Power Transmission Technology Based on Spiral Planar Coil[J]. Electrical Automation,2014,36(2): 78-80.

[2] WANG Guang-hao, WU Yue. Data Trust Model for Road Information in Vehicular Ad hoc Network[J]. Computer Science, 2014,41(6):89-93.

[3] LI Feng, WU Chun- ming. Research on Prevention Fluctuation Control method of Network Intrusion Based on Energy Management[J]. Computer simulation, 2013,30(12): 45-48, 335.

[4] LUO Liang, WU Wen-Jun, ZHANG Fei. Energy Modeling Based on Cloud Data Center[J]. Journal of Software, 2014,25(7):1371-1387.

[5] Song Minghong, Yu Huafeng, Chen Haiyan. Application of Improved Quantum Evolutionary Algorithm in Computer Network's Routing Choice[J]. Bulletin of Science and Technology, 2014,30(1):170-173. 